\title{
Effects of flanker type and position on foveal letter
}

\section{recognition [version 1; peer review: 1 approved, 1 approved with reservations]}

\author{
Mohd Izzuddin Hairol, Qazi Mohamad Omair, Sharanjeet Kaur
}

Optometry \& Vision Science Programme, Faculty of Health Sciences, Universiti Kebangsaan Malaysia, Jalan Raja Muda Abdul Aziz, Kuala Lumpur, 50300, Malaysia

\section{V1 First published: 27 May 2016, 5:1013 \\ https://doi.org/10.12688/f1000research.8572.1}

Latest published: 27 May 2016, 5:1013

https://doi.org/10.12688/f1000research.8572.1

Open Peer Review
Approval Status
version 1
1. Yvonne Norgett, Anglia Ruskin University,
University, Glasgow, UK
Any reports and responses or comments on the
article can be found at the end of the article.

\begin{abstract}
Our ability to identify a foveally viewed letter at resolution threshold reduces when flankers are placed at a certain distance from it, compared to when it is presented on its own. In this study, we investigated how type and position of flankers influences foveal letter recognition. We measured participants' performance to identify unflanked Sheridan-Gardiner letters ( $\mathrm{A}, \mathrm{H}, \mathrm{O}, \mathrm{U}, \mathrm{T}, \mathrm{V}$ or $\mathrm{X})$, using a seven-alternative-forced-choice paradigm with the method of constant stimuli to obtain $80-90 \%$ correct response. Performance was measured again to identify a target letter in the presence of different flanker types. Flankers were bars and letters (placed either to the left and right of the target, above and below the target or on four sides of the target), and a surrounding box. Separation between the target letter and flankers varied between zero (abutting) and ten stroke widths (two letter sizes). For all flanker types, separation between the target ad the flankers significantly influenced performance (all $p<$ $0.0001)$. Flankers abutting the target and at separation of one stroke width caused the largest reduction in performance, regardless of flanker type. For bar flankers, the largest drop in performance (up to 50 percent) occurred with bars placed on all four sides of the target. For letter flankers, flankers placed above and below the target reduced performance as much as four surrounding flankers. At separation of one stroke width, flanking letters and bars caused a further $10 \%$ reduction in performance than a surrounding box. Our results would have significant implications on the design of crowded visual acuity charts, especially those that are available on the market, which have different crowding features between them.
\end{abstract}

Keywords

Letter recognition, contour interaction , crowding , visual acuity 
Corresponding author: Mohd Izzuddin Hairol (izzuddin.hairol@ukm.edu.my)

Competing interests: No competing interests were disclosed.

Grant information: The author(s) declared that no grants were involved in supporting this work.

Copyright: @ 2016 Hairol MI et al. This is an open access article distributed under the terms of the Creative Commons Attribution License, which permits unrestricted use, distribution, and reproduction in any medium, provided the original work is properly cited. Data associated with the article are available under the terms of the Creative Commons Zero "No rights reserved" data waiver (CC0 1.0 Public domain dedication).

How to cite this article: Hairol MI, Omair QM and Kaur S. Effects of flanker type and position on foveal letter recognition [version 1; peer review: 1 approved, 1 approved with reservations] F1000Research 2016, 5:1013

https://doi.org/10.12688/f1000research.8572.1

First published: 27 May 2016, 5:1013 https://doi.org/10.12688/f1000research.8572.1 


\section{Introduction}

Clinically, crowding is the reduction in visual acuity for a target letter presented together with other crowding features, such as other letters, a surrounding box or contours, compared with acuity measured with single letters (Flom et al., 1963; Stuart \& Burian, 1962). Flom et al. (1963) reported that performance for localising the gap of a Landolt $\mathrm{C}$, at acuity level, is reduced by flanking bars that are placed less than one optotype width away from the Landolt C. This effect has been specifically named as contour interaction, to describe the effects of surrounding contours on acuity. Crowding and contour interaction are sometimes used interchangeably, although the latter is considered as a subset of crowding and is usually defined specifically as reduction in acuity by nearby contours (Danilova \& Bondarko, 2007; Flom et al., 1963; Flom, 1991; Formankiewicz \& Waugh, 2013). Besides contour interaction, other factors that influence crowding effects include gaze control inaccuracy and attentional factors (Flom et al., 1963).

When tested with commercially available paediatric acuity tests, Norgett \& Siderov (2014) reported that contour interaction had a greater effect in children than in adults. The younger children group (up to 6 years 9 months in age) had worse acuity for crowded letter charts compared to the older children group (up to 9 years 8 months in age), which could be explained by their underlying development of accurate gaze control and fixational eye movements. Other studies have also reported that contour interaction occurs over a larger distance in children than in adults (Jeon et al., 2010; Semenov et al., 2000). This suggests contour interaction (and crowding), and their associated factors including accuracy of fixational eye movement and attention are attributable to age.

Typically, the crowding effects described above were measured with the flanking features surrounding all four sides of a target letter (or letters). However, it has been shown that in a square $\mathrm{C}$ acuity task, performance of adult observers was differently affected by two flanking bars, dependent on whether they were placed orthogonal or parallel to the gap of the C (Liu, 2001). This indicates that although the oculomotor and attentional components have matured in adult observers, contour interaction effects are still dependent on the relative position of the crowding features from the target.

When measured in the peripheral vision of adults, crowding effects are greater in magnitude when the flankers are similar to the target letter, compared to when they are dissimilar (Bernard \& Chung, 2011; Kooi et al., 1994; Leat et al., 1999). In the adult fovea, however, conflicting results on the effects of flanker type on crowding magnitude have been reported. In the adult fovea, crowding effects can be similar in magnitude, regardless of whether the flankers that are different or similar to the target letter (Leat et al., 1999; Norgett \& Siderov, 2014). Norgett \& Siderov (2011) showed that, in adults, crowding effects are similar for single letters surrounded by either four bars or four letter flankers, placed half a letter width away. However, it is unclear if crowding is still similar when the number of flankers is reduced and when they are independently placed at various distances from the target letter. For close targetflanker separations, letter flankers can result in greater levels of crowding (e.g. Lalor et al., 2016) which could be due to greater similarity between the flankers and the target (Bernard \& Chung, 2011; Kooi et al., 1994).
Knowledge on crowding and contour interaction has been applied in the design of crowded acuity tests, based primarily on the results reported by Flom et al. (1963). Flom et al. reported that the largest reduction in performance to discriminate the gap of a Landolt $\mathrm{C}$ occurred when contours were placed at edge-to-edge distance of two stroke widths away from the target. In paediatric patients, accurate measurement of visual acuity is important to detect visual conditions such as amblyopia, hence allowing accurate monitoring of the response to any prescribed treatment. Amblyopia is clinically diagnosed using acuity tests designed to induce crowding, as it is known that crowding effect may be greater in amblyopes than in patients with normal vision (Hess et al., 2001; Levi et al., 2002). Commercially available crowded acuity tests however, used different target-flanker spacing, flanker type, and optotype arrangement. Generally, in children's acuity charts, flankers (which could be a surrounding box, other letters or contour) are placed at half an optotype width away or one optotype width away from the target. The target itself could be a letter, a string of letters, pictures or symbols and the surrounding flankers could be other letters, a box, or the combination of both (Atkinson et al., 1988; Kay, 1983; Salt et al., 2007). These differences may produce different amount of crowding exerted possibly affecting their sensitivity to detect amblyopia.

The aims of this study were (1) to compare crowding produced by different number of flankers and by different flanker types, and (2) to determine the optimum separation between target and flankers that produce maximum crowding. The results would have an application in designing a clinical letter test that would exert maximum crowding effects. The test could then be more sensitive in detecting visual conditions that are characterised by crowding, such as in amblyopia, where acuity is worse when tested with a crowded target than when it is measured with isolated letters.

\section{Methods}

\section{Participants}

Eight participants were involved in this study, based on convenience sampling. All participants had best-corrected visual acuity of $6 / 6$ or better in both eyes, healthy, and had no significant ocular or systemic diseases. This research was approved by Universiti Kebangsaan Malaysia's Researc Ethics Committee (NN-2014-083), which complied with the tenets of the Declaration of Helsinki. All participants provided written informed consent before the start of the experiment.

\section{Apparatus}

The experiment was run on a Macintosh desktop, where Matlab (version R2012a) with PsychToolbox version 3.0.8 extension (Pelli, 1997) was installed to create the experimental stimuli. Stimuli were digitised Sheridan Gardiner letters (A, H, O, T, U, V, and X), scanned from their printed clinical chart format. Each letter had a $5 \times 5$ construction, that is, each stroke was one fifth of the letter size and each letter had equal width and height. The Weber's contrast of the letters was $90 \%$. Stimuli were displayed on a Samsung CRT monitor running at $100 \mathrm{~Hz}$.

\section{Procedure}

In this study, we measured contour interaction and crowding functions for visual acuity (Flom et al., 1963). First, we measured performance of each participant to identify an isolated target letter. 
The physical size of the letter displayed on the computer screen was fixed. Isolated letters were presented randomly for 100 trials and participant's responses were recorded. A viewing distance was chosen (between 11 and 13 metres) so that the percent correct response fell between 80 to 90 percent for each participant. All participants completed four 100-trial runs. Performance across the four runs was averaged to obtain the unflanked (i.e. uncrowded) performance.

Next, the participant's task was to identify the target letter in the presence of crowding features. When the target letter was flanked by bars, the separation between them was expressed in edge-to-edge separations of $0,1,2.5,3.5,5$, and 10 stroke-widths (each strokewidth is equivalent to one fifth of the target letter size). The bars were placed either horizontally, that is, to the left and right of the target letter (Figure 1a); vertically, that is, above and below the target letter (Figure 1b); or at the top, bottom, left and right to the target letter (Figure 1c).

For letter flankers, the separation between the target letter and its flankers were calculated as the distance from the centre of the target to the centre of one of the flanking letters. Hence, separations between them were expressed in centre-to-centre units, which were $1,1.25,1.5,1.75,2$ and 3 . Note that centre-to-centre separation of 1 is equivalent to zero stroke-width in edge-to-edge units (i.e., two closest edges of the target and flanking letters were abutting). The flanking letters were placed either horizontal to the target letter (to the left and right of the target letter, Figure 1d); vertical to the target letter (above and below it, Figure 1e); or, at the top, bottom, left and right of the target letter (Figure 1f). Additionally, performance was also measured when the target letter was enclosed in a box (Figure 1g). The stroke of the box was one-fifth of the target letter size. The crowding features were always of the same contrast as the target letter. When letters were used as the crowding feature, they were never the same letter as the target and were always different from each other.

Table 1 summarises the separation between target and flankers used in the study, expressed in edge-to-edge units for bar flankers and surrounding box, and centre-to-centre units for letter flankers. Conversion from centre-to-centre units to edge-to-edge units is also shown, to allow direct comparisons of the effects of the different types of flankers on letter recognition.

All participants completed four runs of each crowding condition. There were 100 trials in each run. Within each run, the target letter and the separation between the target and its crowding feature was randomised. In this part of the experiment, isolated letters (i.e. unflanked) were also included in some of the trials, with an equal probability of being displayed as the flanked letter trials. All experimental runs were conducted in a systematic order. Runs with flanking bars were completed first, followed by runs with flanking letters and runs with the surrounding box. In total, each participant completed 3200 trials, excluding practice trials.

Participants indicated their response verbally. The response was then entered by the examiner using a keyboard. No feedback was given. Viewing time was unlimited, that is, participants were allowed to take their time to identify the target letter, although generally the responses were prompt. With each keyboard input, the stimulus display was replaced by a mean luminance screen that appeared for $500 \mathrm{~ms}$ before the presentation of the next trial. Testing was done monocularly using the subject's dominant eye, determined with the hole-in-hand test (Miles, 1930). The non-viewing eye was covered with a black occluder. All participants were given training with the task and data collection only commenced after they were comfortable with the experimental procedures (at least two hours of training). Data collected during the training period were not included in the final analysis.

\section{Statistics}

Raw data were sorted in MS Excel version 14 and plotted in IgorPro $^{\mathrm{TM}}$ version 6.3.6.4 (WaveMetrics, Portland, OR). Statistical analyses were carried out using IBM Statistical Package for Social Sciences (SPSS) version 19.0. Data were analysed using repeated measures Analysis of Variance (ANOVA) with Greenhouse-Geisser correction to compare change in performance obtained with the different flanker types and positions. Post hoc pairwise comparisons with Benferroni corrections were performed where appropriate. Alpha level of 0.05 was used for all statistical tests.

\section{Results}

\section{Dataset 1. Percent correct performance for target identification}

http://dx.doi.org/10.5256/f1000research.8572.d120563

S\#: Participant number

Figure 2 shows relative performance to identify the target letter as a function of target-flanking bar separation. Relative performance was calculated by subtracting the performance with flanking bars from performance to recognise an unflanked target. Therefore, performance lower than $0 \%$ correct for a flanked condition indicates a performance lower than that found for unflanked condition, i.e. crowding. Likewise, performance greater than $0 \%$ correct for a flanked condition indicates that participants' correct responses for a flanked condition were higher than an unflanked condition.

Repeated measures ANOVA revealed significant main effects of position $\left[\mathrm{F}_{(1.67,11.71)}=9.43, p=0.005\right]$ and target-flanker separation $\left[\mathrm{F}_{(1.74,12.17)}=21.05, p<0.001\right)$ on relative performance. The interaction between the position of flanking bars and target-bar separation was significant $\left[\mathrm{F}_{(3.58,25.07]}=3.95, p=0.02\right]$. That is, the change in relative performance for identifying the target across separation was influenced by the position (and number) of the flanking bars. Two flanking bars placed at the bottom and top of the target (open triangles in Figure 2) exerted the least crowding effect that was significantly different from that obtained with four flanking bars $\left[\mathrm{F}_{(1,7)}=13.07, p<0.01\right]$. Performances with two flanking bars placed to the left and right of the target (open diamonds in Figure 2) and four bars surrounding the target (open circles in Figure 2) were not significantly different $\left[\mathrm{F}_{(1,7)}=5.14, p=0.06\right]$. The extent of crowding was also different dependent on the position of the flankers. Post hoc tests revealed that performance with top and bottom bars was significantly lower from unflanked conditions at separations of $0(p=0.005)$ and $1(p=0.001)$. With left and right 
a

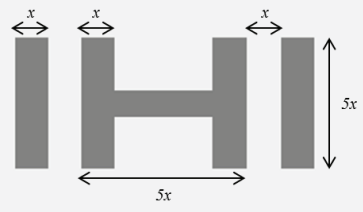

C

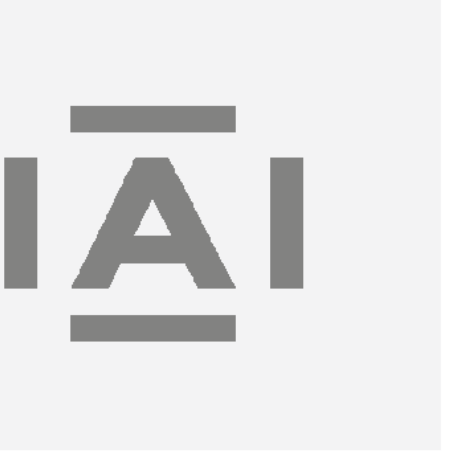

e

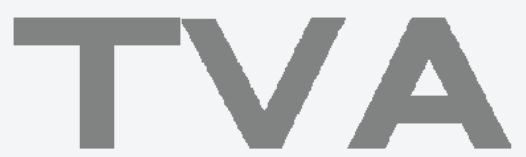

b

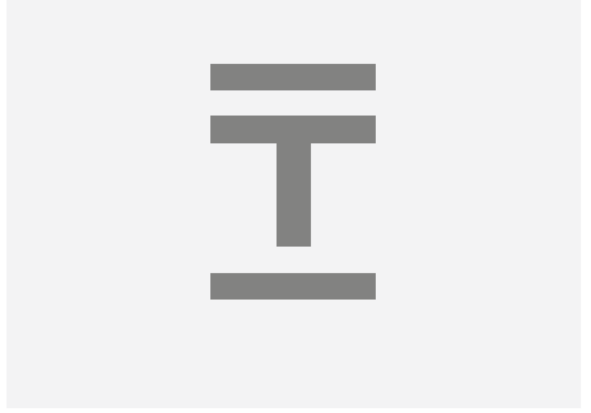

d

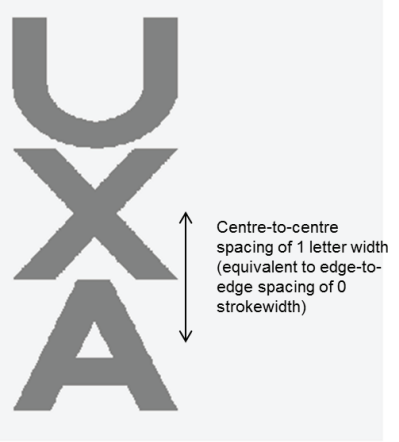

f

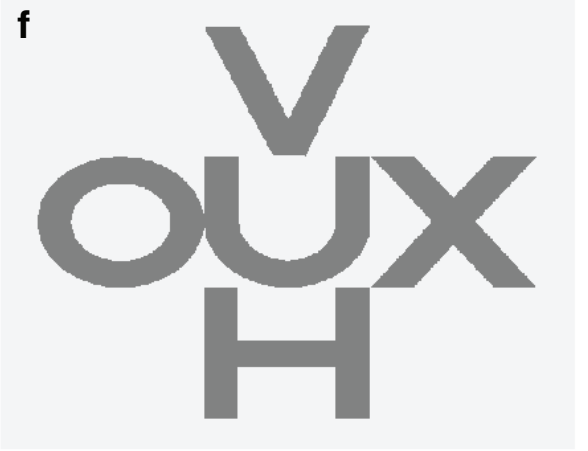

g

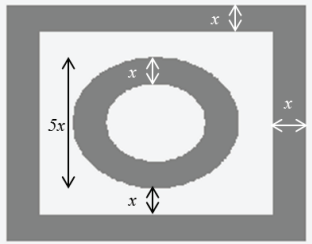

Figure 1. a. Target letter $\mathrm{H}$ flanked horizontally by two vertical bars. The size of each stroke of the letter $(\mathrm{x})$ is one fifth of the whole letter size (which is 5x). The width of the flanking bars is one stroke-width and the length of the bars is the same to that of the target letter. The separation shown here is one stroke-width, where separation is measured from the closest edge of the target letter to the closest edge of the flanking bars. b. Target letter T flanked vertically by two horizontal bars. c. Target letter A flanked by four bars on all its sides. d. Target letter $V$ flanked horizontally by two other letters. The centre-to-centre separation between target and flankers shown here is one letter width, which is equivalent to edge-to-edge separation of zero stroke-width, i.e. the target abuts the flankers. e. Target letter X flanked vertically by two other letters. $\mathbf{f}$. Target letter $U$ flanked on four sides by four other letters. $\mathbf{g}$. Target letter $\mathrm{O}$ enclosed in a crowding box. The stroke-width of the box is the same as the stroke-width of the target letter. The separation between the closest edge of the letter and the box shown here is one stroke-width. 
Table 1. The separations between target letter and flanking bars and box are expressed in stroke-width units. The separations between target letter and flanking letters are expressed as centre-to-centre units and their edge-to-edge equivalent.

\begin{tabular}{|c|c|c|}
\hline Bar flankers and box & \multicolumn{2}{|c|}{ Letter flankers } \\
\hline $\begin{array}{c}\text { Edge-to-edge spacing } \\
\text { (stroke-width) }\end{array}$ & $\begin{array}{c}\text { Centre-to- } \\
\text { centre spacing }\end{array}$ & $\begin{array}{c}\text { Edge-to-edge } \\
\text { equivalent (stroke- } \\
\text { width) }\end{array}$ \\
\hline 0 & 1 & 0 \\
\hline 1 & 1.25 & 1.25 \\
\hline 2.5 & 1.50 & 2.50 \\
\hline 3.5 & 1.75 & 3.75 \\
\hline 5.0 & 2.0 & 5.0 \\
\hline 10.0 & 3.0 & 10.00 \\
\hline
\end{tabular}

bars, performance was significantly lower from unflanked conditions at separations of $0(p<0.001), 1(p=0.003)$ and $2.5(p=0.006)$ stroke widths. With four surrounding bars, performance was also significantly lower from unflanked conditions at separations of 0 $(\mathrm{p}<0.001), 1(\mathrm{p}<0.001)$ and $2.5(\mathrm{p}=0.004)$ stroke widths.
Figure 3 shows relative performance to identify the target letter as a function of separation between the target and flanking letters. Repeated measures ANOVA revealed that there was significant main effects of flanker position $\left[\mathrm{F}_{(1.36,9.54)}=10.53, p=0.006\right]$ and separation $\left.\mathrm{F}_{(1.98,13.88)}=62.54, p<0.001\right]$ on relative performance. There was a significant interaction between flanking letter position and target-flanker separation $\left[\mathrm{F}_{(2.79,19.56)}=6.54, p=0.004\right]$. Unlike with flanking bars, letter flankers placed at the top and bottom of the target letter (open triangles, Figure 3) exerted as much crowding as, and not significantly different from, that obtained with four letter flankers (filled circles in Figure 3) placed around the target $\left[\mathrm{F}_{(1,7)}=0.02, p=0.88\right]$. Least reduction of performance was obtained by two letter flankers that are placed to the left and right of the target (open diamonds in Figure 3) and it was significantly different from that obtained with four letter flankers $\left[\mathrm{F}_{(1,7)}=47.41, p<0.001\right]$. Post hoc tests showed that performance with left and right letter flankers was significantly lower than unflanked performance at separations of 0 and 1.25 centre-to-centre. For top and bottom, and four surrounding letter flankers, performance was significantly lower from unflanked conditions at separations of $0,1.25$ and 2.5 centre-to-centre (all $p<0.05$ ). That is, the extent of crowding was larger for these two stimulus configurations.

Figure 4 compares relative performances in identifying the target when it was flanked by four bars, four flanking letters and when

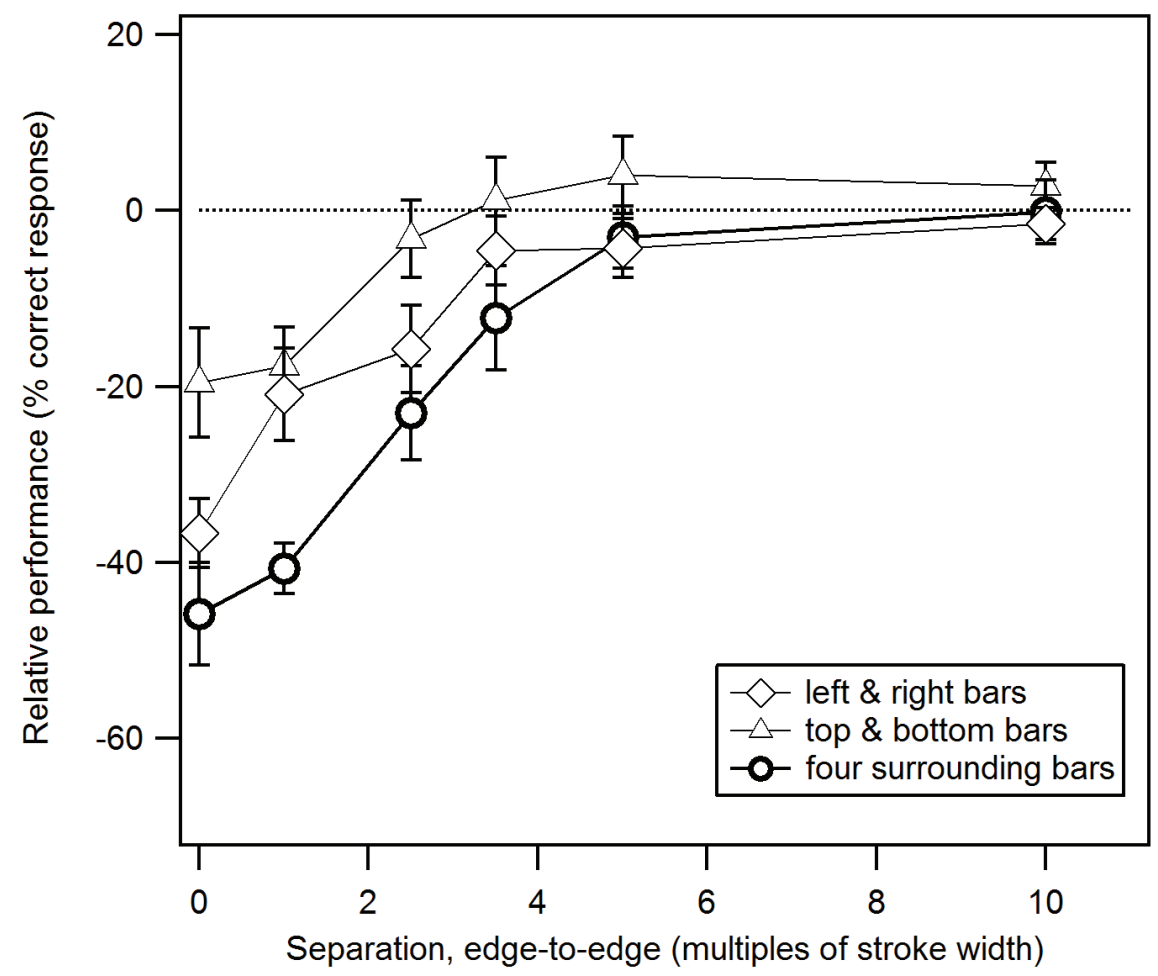

Figure 2. Relative performances (\% correct response) to identify the target letter flanked by two bars placed to the right and left of the target (i.e. horizontal arrangement, open diamonds), and above and below of the target letter (i.e. vertical arrangement, open triangles). Relative performance was also measured for a target flanked by four bars (open circles). Performances are shown as a function of target-flanker separation. 


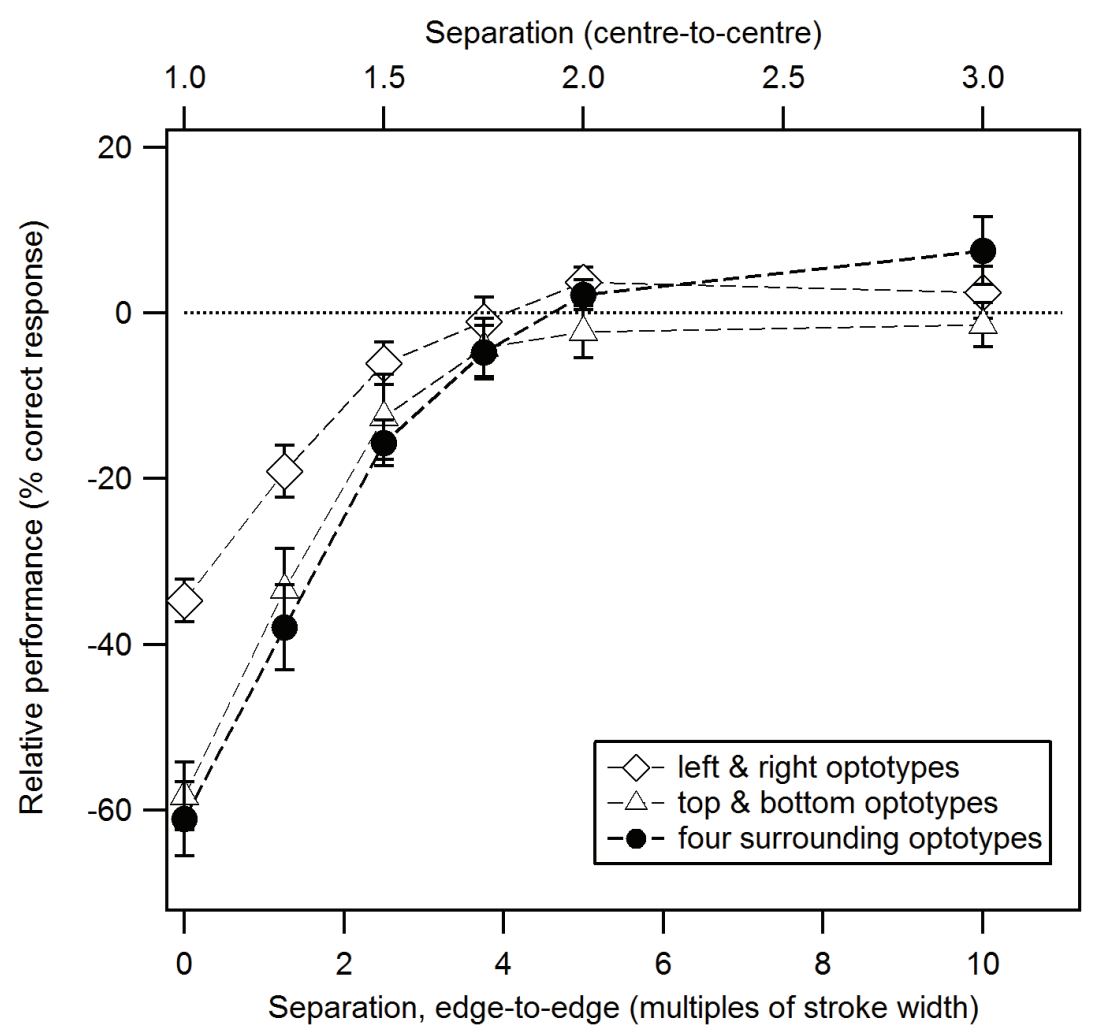

Figure 3. Relative performances (\% correct response) to identify the target letter flanked by two other optotypes placed to the right and left (open diamonds), above and below (open triangles), of the target letter, and four optotypes surrounding it (filled circles) as a function of target-flanker separation.

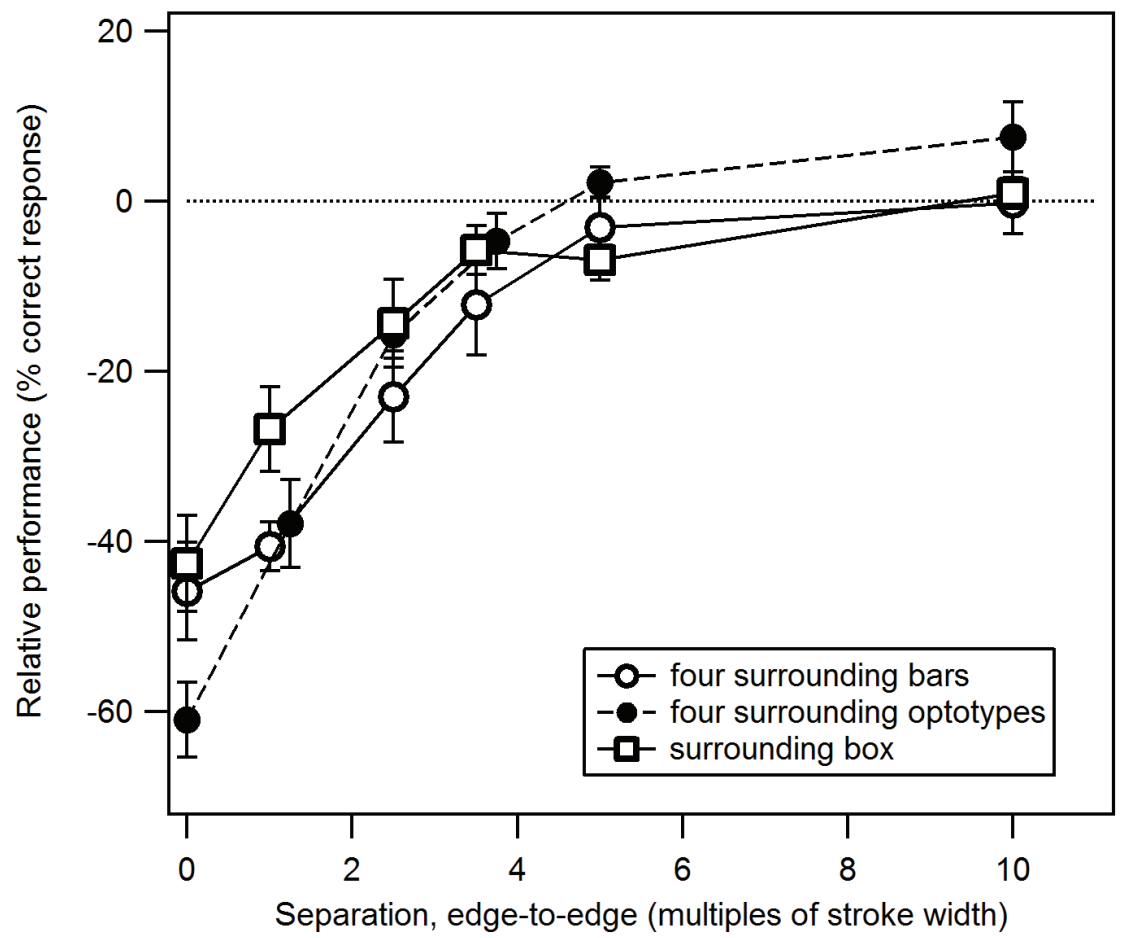

Figure 4. Relative performances (in percent of correct response) to identify a target letter flanked by four bars (open circles), four optotypes (closed circles) and a surrounding box (open squares), as a function of target-flanker separation (in multiples of stroke width). 
it was surrounded by a box. For all types of flankers, the largest reduction in performance occurred when the flankers abutted the target. Generally, participants' relative performance to identify the target letter was similar for a target flanked by either four letters or four bars. At separation of one stroke width, the surrounding box appeared to exert the least crowding effect compared to other types of flankers. Repeated measures ANOVA reveals that the interaction between flanker type and separation is significant $\left[\mathrm{F}_{(3.42,23.92)}=\right.$ $3.15, p=0.038$ ), that is, the change in relative performance across separation was dependent on the flanking features used. Post hoc analyses revealed that a significant difference in performance with the different flanker types only occurred between letter flankers and box, when they abutted the target letter ( $p=0.007$ ), but not for bar flankers and at all other separations. The difference between flanked and unflanked performances occurred at a separation of 0,1 and 2.5 stroke widths. This extent of crowding was similar to that found when four bars and four letter flankers were used.

\section{Discussion}

Our results are consistent with earlier findings that flanking bars reduced the recognition of a foveally fixated acuity target when they are in close proximity to each other (e.g. Flom et al., 1963; Stuart \& Burian, 1962). Regardless of the type of the flankers used recognition of a target letter was similarly affected when there were four flankers surrounding it. Our results obtained with four surrounding letters and bars are consistent with the observations of Norgett \& Siderov (2014) in adult observers. Other studies have also reported that with adult foveal viewing, crowding effects were similar for flankers that are categorically similar and dissimilar to the target (Danilova \& Bondarko, 2007; Leat et al., 1999; Song et al., 2014). Norgett \& Siderov (2014) reported that in children however, at separation half a letter width away (i.e. 2.5 stroke-widths) significantly larger foveal crowding effects were observed with letter flankers compared to four flanking bars. In our study, other than in the abutting condition, the largest reduction of performance occurred with target-flanker separation of one stroke-width. It is likely that larger crowding effects in children than adults would also be observed with flankers placed at one stroke-width away from the target.

We also showed that the reduction in correct performance was dependent on the number and relative position of the flankers surrounding the target. Other than the abutting condition, separation of about one stroke-width, edge-to-edge, exerts the most crowding effect for all conditions. However, at this target-flanker separation, the position of the flankers relative to the target letter influenced the magnitude of the crowding effect. Liu (2001) reported different patterns of performance for a square $\mathrm{C}$ orientation discrimination task when it was flanked by two bars that was dependent on the flanker's position relative to the gap of the C, i.e. either parallel or orthogonal to the C's gap. Therefore, if a crowded chart is to be developed using bars as the crowding feature, maximum crowding can be exerted with flanking bars placed either to the left and right or on all four sides of the target letter with a separation of one stroke width.

With two letter flankers, reduction in performance is significantly dependent on their position relative to the target letter. We observed the least crowding when the letters were place to the left and right of the target letter, especially when they were abutting and at approximately one stroke-width away from the target (Figure 3), compared to when they were placed above and below the target letter. Asymmetric horizontal-vertical crowding region have been reported when target and distractors are presented in the peripheral visual field (Feng et al., 2007; Hairol et al., 2014; Toet \& Levi, 1992). An interesting observation is that two letter flankers placed at the top and bottom of the target letter reduced the participants' performance just as much as having four letter flankers surrounding the target. Cherici et al. (2012) reported that for normal adults, prolonged fixation was inaccurate during foveal fixation, and the eye movement range when one was fixating may be larger than the spacing between letters at size threshold. It could be assumed that crowding would be similar regardless of whether a target letter is flanked vertically or horizontally by other letters. Indeed, a similar amount of crowding has been reported for a single letter surrounded by four letters on all its sides and for a string of five letters surrounded by other letters (Norgett \& Siderov, 2014). Bedell et al. (2015) reported that more errors were made by adult observers when identifying a long string of letters compared to a short string of letters (all were arranged horizontally). However, it is unclear how error rate would differ for a string of vertically arranged letters. We showed that performance was reduced further for a target letter flanked vertically by other letters than that for letters that are flanked horizontally (Figure 3). As most adults are presumably more trained for reading letters that are arranged horizontally (as was the case for all participants in this study) there could be less fixation inaccuracies when letters are read horizontally compared to when the letters are read vertically. It has been shown that reading rate is similar for experienced adults who are trained to read either horizontal or vertical texts (Sun et al., 1985; see also Rayner, 1998). This implies that horizontal-vertical asymmetry in crowding is not necessarily a fixed characteristic but most likely it is experienceand skill-dependent.

Particular attention should be given to the type of flankers used to induce crowding and contour interaction effects. We showed that when a surrounding box was placed at 2.5 stroke-widths (half a letter width) away from the target, the magnitude of crowding was not significantly different from that produced by either four letters or four bars, indicating that at this particular target-flanker separation, similar outcome would be found regardless of the flanker type. However, when placed at one stroke-width away from the target letter, flanking letters and bars caused approximately a further $10 \%$ reduction in performance to identify the target letter, compared to a surrounding box although this difference in performance did not reach statistical significance. Similar results have also been reported previously (Lalor et al., 2012). This may be of clinical implication since a number of crowded letter charts, designed to induce crowding, use a box as a crowding feature to surround the target letter (e.g. McGraw \& Winn, 1993; Salt et al., 2007).

Various acuity tests designed to induce crowding typically used bars or other letters as their crowding feature, such as the logMAR crowded test, the Cambridge Crowding Cards and Sonksen LogMAR test. The separation between the target letter and the crowding feature typically is half an optotype width (but for the Sonsken $\log$ MAR test, the separation is one letter width). 
Formankiewicz \& Waugh (2013) suggested that crowding in acuity tests could be enhanced by placing flankers closer to the target letter than in the currently available test. Our results complement this suggestion, where we also showed that larger magnitude of crowding can be obtained, at least for recognising single letters, if the crowding feature is placed at a distance closer than those designed in commercially available charts, specifically at one stroke-width away ( 0.2 letter width) from the target. At this particular separation, similar crowding magnitude was obtained with either letter or bar flankers. Indeed, larger foveal crowding effects have been reported for flankers that are placed closer than half a letter width away from an acuity target (Flom, 1991; Formankiewicz \& Waugh, 2013; Lalor et al., 2016; Norgett \& Siderov, 2014). Therefore, this separation could be considered in future designs of clinical acuity charts, so that these charts could be more sensitive in detecting eye conditions that suffer from crowding such as amblyopia. However, a surrounding box at this same separation produced approximately $10 \%$ less reduction of performance compared to other types of flankers. It has been reported that crowding reduces when flankers are grouped together, possibly aiding target recognition (for example, extending bars to form a surrounding box) (Banks \& White, 1984; Manassi et al., 2012; Sayim et al., 2011).

In this study, abutting condition consistently produced the maximum amount of crowding, regardless of the flanker number or type. However, one must be careful when considering it in the design of clinical acuity charts. It has been observed that performance to localise the gap of a Landolt $\mathrm{C}$ was better when flankers abutted the target, compared to when the flankers were about 1 or 2 stroke widths away (Danilova \& Bondarko, 2007; Flom et al., 1963). However, it was also reported that abutting flankers elicited the largest crowding magnitude compared to other target-flanker separations for localising the gap of a square C (Hairol et al., 2013) and for acuity measured with picture and letter optotypes (Formankiewicz \& Waugh, 2013). Abutting may be a special case of crowding. When flankers and the target are just abutting, this combination may change the overall appearance of the target letter. It has been shown that dioptric blur reduces the amount of crowding obtained in abutting condition (Formankiewicz \& Waugh, 2013) which would predict that those with uncorrected refractive error (or perhaps anisometropic amblyopia) would perform better than those with normal vision. Hence realistically, the spacing that exerts crowding is preferably not when the flankers are touching target.

\section{Conclusions}

Recognition of letters in foveal viewing is influenced by the distance, type and number of flankers surrounding them. When a letter is surrounded by only two letter flankers, crowding magnitude differ significantly, depending whether they are in vertically- or horizontally-arranged configurations. This effect is possibly due to imprecise eye movements when extracting the target from the flankers, which could be experience- and skill-dependent. The magnitude of crowding is similar for a target surrounded by flankers at all four sides, regardless of the flanker type, at a target-flanker separation of half optotype width, which is widely used in commercially available crowded clinical charts. Maximum crowding can be induced at target-flanker separation of one stroke width (equivalent to 0.2 optotype width) when the target is surrounded on all four sides by either bars or other letters. A box however produces slightly less crowding effect, although not statistically significant, at this particular target-flanker separation. Our results have implications on the future designs of acuity tests that aim to exert the maximum crowding effect, so that they become more sensitive in detecting certain eye conditions such as amblyopia.

\section{Data availability}

F1000Research: Dataset 1. Percent correct performance for target identification, 10.5256/f1000research.8572.d120563 (Hairol et al., 2016).

\section{Consent}

Written informed consent for publication of their clinical data was obtained from the participants.

\section{Author contributions}

MIH and SK conceived the study. MIH designed the experiments with contributions from QMO, and QMO carried out the experiment. MIH prepared the first draft of the manuscript and QMO and SK contributed in subsequent drafts. All authors were involved in the revision of the manuscript and have agreed to the final content.

\section{Competing interests}

No competing interests were disclosed.

\section{Grant information}

The author(s) declared that no grants were involved in supporting this work.

\section{Acknowledgements}

We thank the staff of Optometry Clinic, Faculty of Health Sciences, UKM for their co-operation during the conduct of this study.
Atkinson J, Anker S, Evans C, et al:: Visual acuity testing of young children with the Cambridge Crowding Cards at 3 and 6 m. Acta Ophthalmol (Copenh). 1988; 66(5): 505-508.

PubMed Abstract | Publisher Full Text

Banks WP, White H: Lateral interference and perceptual grouping in visual detection. Percept Psychophys. 1984; 36(3): 285-295.

PubMed Abstract | Publisher Full Text
Bedell HE, Siderov J, Formankiewicz MA, et al:: Evidence for an eye-movement contribution to normal foveal crowding. Optom Vis Sci. 2015; 92(2): 237-245. PubMed Abstract | Publisher Full Text

Bernard JB, Chung ST: The dependence of crowding on flanker complexity and target-flanker similarity. J Vis. 2011; 11(8): pii: 1

PubMed Abstract | Publisher Full Text | Free Full Text

Cherici C, Kuang X, Poletti M, et al:: Precision of sustained fixation in trained 
and untrained observers. J Vis. 2012; 12(6): pii: 31

PubMed Abstract | Publisher Full Text | Free Full Text

Danilova MV, Bondarko VM: Foveal contour interactions and crowding effects at the resolution limit of the visual system. J Vis. 2007; 7(2): 25.1-18.

PubMed Abstract | Publisher Full Text | Free Full Text

Feng $\mathrm{C}$, Jiang $\mathrm{Y}, \mathrm{He} \mathrm{S}$ : Horizontal and vertical asymmetry in visual spatial crowding effects. J Vis. 2007; 7(2): 13.1-10.

PubMed Abstract | Publisher Full Text

Flom MC: Contour interaction and the crowding effect. Problems in Optometry. 1991; 3: 237-257.

Flom MC, Weymouth FW, Kahneman D: Visual Resolution and Contour Interaction. J Opt Soc Am. 1963; 53(9): 1026-32.

PubMed Abstract | Publisher Full Text

Formankiewicz MA, Waugh SJ: The effects of blur and eccentric viewing on adult acuity for pediatric tests: implications for amblyopia detection. Invest Ophthalmol Vis Sci. 2013; 54(10): 6934-43.

PubMed Abstract | Publisher Full Text

Hairol MI, Abd-Latif N, Woi PJ, et al.: Visual acuity and spatial interaction zones: investigating the periphery in anisometropic amblyopia. J Vis. 2014; 14(10): 772 Publisher Full Text

Hairol MI, Formankiewicz MA, Waugh SJ: Foveal visual acuity is worse and shows stronger contour interaction effects for contrast-modulated than luminance-modulated Cs. Vis Neurosci. 2013; 30(3): 105-20.

PubMed Abstract | Publisher Full Text

Hairol MI, Omair QM, Kaur S: Dataset 1 in: Effects of flanker type and position on foveal letter recognition. F1000Research. 2016.

Data Source

Hess RF, Dakin SC, Tewfik M, et al:: Contour interaction in amblyopia: scale selection. Vision Res. 2001; 41(17): 2285-2296.

PubMed Abstract | Publisher Full Text

Jeon ST, Hamid J, Maurer D, et al:: Developmental changes during childhood in single-letter acuity and its crowding by surrounding contours. $J$ Exp Child Psychol. 2010; 107(4): 423-437.

PubMed Abstract | Publisher Full Text

Kay H: New method of assessing visual acuity with pictures. Br J Ophthalmol. 1983: 67(2): 131-133.

PubMed Abstract | Publisher Full Text | Free Full Text

Kooi FL, Toet A, Tripathy SP, et al:: The effect of similarity and duration on

spatial interaction in peripheral vision. Spat Vis. 1994; 8(2): 255-279.

PubMed Abstract | Publisher Full Text

Lalor SJ, Formankiewicz MA, Waugh SJ: Crowding and visual acuity measured in adults using paediatric test letters, pictures and symbols. Vision Res. 2016; 121: $31-38$

PubMed Abstract | Publisher Full Tex

Lalor SJH, Formankiewicz MA, Waugh SJ: Where should the bars be to produce optimal crowding effects using children's acuity letters, pictures and symbols? In European Academy of Optometry and Optics Conference. Dublin. 2012. 97. Reference Source

Leat SJ, Li W, Epp K: Crowding in central and eccentric vision: the effects of contour interaction and attention. Invest Ophthalmol Vis Sci. 1999; 40(2): 504-512. PubMed Abstract
Levi DM, Hariharan S, Klein SA: Suppressive and facilitatory spatial interactions in amblyopic vision. Vision Res. 2002; 42(11): 1379-1394.

PubMed Abstract | Publisher Full Text

Liu L: Dual oriented mechanisms in contour interaction. Vision Res. 2001; 41(7): 853-858.

PubMed Abstract | Publisher Full Tex

Manassi M, Sayim B, Herzog MH: Grouping, pooling, and when bigger is better in visual crowding. $J$ Vis. 2012; 12(10): 13.

PubMed Abstract | Publisher Full Text

McGraw PV, Winn B: Glasgow Acuity Cards: a new test for the measurement of letter acuity in children. Ophthalmic Physiol Opt. 1993; 13(4): 400-404.

PubMed Abstract | Publisher Full Text

Miles WR: Ocular dominance in human adults. J Gen Psychol. 1930; 3(3):

412-430.

Publisher Full Text

Norgett $\mathrm{Y}$, Siderov J: Crowding in children's visual acuity tests--effect of test

design and age. Optom Vis Sci. 2011; 88(8): 920-927.

PubMed Abstract | Publisher Full Text

Norgett $\mathrm{Y}$, Siderov J: Foveal crowding differs in children and adults. $J$ Vis. 2014; 14(12): pii: 23

PubMed Abstract | Publisher Full Text

Pelli DG: The VideoToolbox software for visual psychophysics: transforming numbers into movies. Spat Vis. 1997; 10(4): 437-442.

PubMed Abstract | Publisher Full Text

Rayner K: Eye movements in reading and information processing: 20 years of research. Psychol Bull. 1998; 124(3): 372-422.

PubMed Abstract | Publisher Full Text

Salt AT, Wade AM, Proffitt R, et al.: The Sonksen logMAR Test of Visual Acuity: I. Testability and reliability. J AAPOS. 2007; 11(6): 589-596.

PubMed Abstract | Publisher Full Text

Sayim B, Westheimer G, Herzog MH: Quantifying target conspicuity in contextual modulation by visual search. $J$ Vis. 2011; 11(1): 6 .

PubMed Abstract | Publisher Full Text

Semenov LA, Chernova ND, Bondarko VM: Measurement of visual acuity and crowding effect in 3-9-year-old children. Hum Physiol. 2000; 26(1):

$16-20$.

Publisher Full Text

Song S, Levi DM, Pelli DG: A double dissociation of the acuity and crowding limits to letter identification, and the promise of improved visual screening. J Vis. 2014; 14(5): 3

PubMed Abstract | Publisher Full Text | Free Full Text

Stuart JA, Burian HM: A study of separation difficulty. Its relationship to visual acuity in normal and amblyopic eyes. Am J Ophthalmol. 1962; 53(3):

471-477.

PubMed Abstract | Publisher Full Text

Sun F, Morita M, Stark LW: Comparative patterns of reading eye movement in Chinese and English. Percept Psychophys. 1985; 37(6): 502-506.

PubMed Abstract | Publisher Full Text

Toet A, Levi DM: The two-dimensional shape of spatial interaction zones in the parafovea. Vision Res. 1992; 32(7): 1349-1357.

PubMed Abstract | Publisher Full Text 


\title{
Open Peer Review
}

\section{Current Peer Review Status:}

\section{Version 1}

Reviewer Report 04 July 2016

https://doi.org/10.5256/f1000research.9224.r14037

(C) 2016 Jeon S. This is an open access peer review report distributed under the terms of the Creative Commons Attribution License, which permits unrestricted use, distribution, and reproduction in any medium, provided the original work is properly cited.

\author{
Seong Taek Jeon \\ Vision Research Group, Department of Vision Sciences, Glasgow Caledonian University, Glasgow, \\ UK
}

\section{Reviewer's General Summary}

The current research investigated the effect of type (bars vs. optotype) and position (top-andbottom vs. side-by-side vs. all four sides) of flankers on foveal crowding (It was not clear if the surrounding box was a separate factor or level within the type or position). The aims of the study were two-folds: the authors tried to (1) compare how the above-listed factors affect the foveal crowding in terms of performance change relative to the reference uncrowded acuity, which is individually determined to yield 80 to $90 \%$ correct identification. (2) find the optimum separation between target and flankers that produce maximum crowding, where they found the optimal separation to be the abutting condition, not the single stroke-width, regardless of flanker type as well as position.

Overall, the effect of flanker positions was presented in a series of figures by each flanker type, where the effect of crowding was greatest with four bars, followed by the left-and-right bars with top-and-bottom bars showing the minimum crowding (Figure 2). Similarly, the effect of crowding was maximised when all four sides of the target were surrounded by optotypes. However, crowding was minimal with left-and-right optotypes while the effect of crowding with the top-andbottom condition was tantamount to that in four surrounding optotypes, which is different from when bars were used as flankers (Figure 3). The effect of surrounding box was compared to different flanker types only with four sides conditions, where the effect of crowding among the surrounding bars, optotypes, and box was more or less similar (Figure 4).

More specific comments can be found below. The reviewer recommends the paper to be accepted with the reservation that the authors address the issues in the specifics satisfactorily.

\section{Method \& Procedure}

What were the size of the monitor and its pixel resolution?

Given the unusually long viewing distance (11 to 13 metres), I gather the experiments were 
conducted in some sort of long hallway. Please describe the place and lighting condition with overall luminance level.

Missing age and gender information of the participants.

In Figure 1, sample stimulus pictures are not correctly scaled.

In Figure 2-4 what are the error bars representing?

It is strongly recommended the authors provide the individual viewing distance and threshold letter size in visual angle along with the relative performance.

For the uncrowded performance, I am wondering if the authors tried any item analysis for each individual letters to see how each letter fared across observers. It has been shown (e.g. , Bernard \& Chung, 2011; Hanus \& Vul, 2013; Liu \& Arditi, 2001) that there are some differences in detectability among letters. This came to the reviewer's attention due to the possible imbalance in the current experimental design, which is detailed below.

It was not clear to me if the surrounding box condition was treated as a separate factor or a level under flanker configuration or flanker type. This is critical since it is directly relevant to your analyses to follow. If I am not mistaken, the total number of conditions tested is 37 , which is calculated from the combination of 6 target-to- flanker separations $\times 3$ flanker positions (top-to-bottom vs.side-by-side vs. all four sides) $X 2$ flanker features/types (bars vs. optotypes) and an extra condition with a surrounding box flanker. With this number of conditions, I am confused how you can possibly counterbalance the conditions with seven letters to be equally presented across conditions in both the single letter and crowding condition when the total numbers of trials used were 400 and 3200 respectively. This problem still holds even when I include the surrounding box condition as a level under either flanker feature or position. Together with the possible difference in legibility among the letters, this imbalance can be a serious threat to the validity of the study.

\section{Results \& Analyses}

According to the results, maximum crowding occurs when flankers touch the target regardless of flanker types and positions then the magnitude of crowding monotonically diminishes as a function of target-flanker separation. Especially for the bar flankers, this is somewhat different from the literature and the reviewer's personal experience because bar flankers do not crowd some targets anymore when bars are blended with features of certain letters. For example, when bars are touching the sides to the vertical strokes of an $\mathrm{H}$ as in Figure 1(a) or top and bottom to an upright $\mathrm{T}$ as in Figure 1(b), they become a distinct featural addition to a new amalgamated pattern that can be readily picked up by foveal vision. This in turn may facilitate the identification of the target, which has been demonstrated many times as a dipper curve, instead of smooth and monotonic curve, when performance is plotted as a function of separation (Bedell et al., 2013; Danilova and Bondarko, 2006; Flom, Weymouth, and Kahneman, 1963; Jeon et al., 2010; Simmers et al., 1999). Thus, the monotonic function of crowding shown in the current paper begs explanation or discussion with respect to previous literature.

In relation to the imbalance issue mentioned above, it was not clear whether a single 
omnibus ANOVA or multiple ANOVAs were performed. Furthermore, it is still not clear if the surrounding box condition was treated as a factor or a level. Please make sure to explain clearly how the surrounding box condition was treated in the analysis.

Given the consistent trend in data regardless of flanker type and position where the relative performance monotonically increases as a function of flanker-target separation, a generalised linear modelling with nested model testing seems more appropriate than ANOVA. It will provide a more structured account on how the effect of flanker types and positions changes with respect to separation.

\section{Discussion}

As mentioned in the last paragraph of the introduction that the results would have an application in designing a clinical letter test, I expected in-depth discussion of how the current results can be compared to the existing clinical crowding acuity tests such as Cambridge Crowding Cards (Atkinson et al., 1988) or Glasgow Acuity Cards (McGraw and Winn, 1995). A few insightful recommendations or suggestions on this matter seem to be a nice addition to the current section.

In the $1^{\text {st }}$ sentence of the last paragraph, the authors are saying, "In this study, abutting condition consistently produced the maximum amount of crowding, regardless of the flanker number or type," which is not consistent with the abstract where they said, "Flankers abutting the target and at separation of one stroke width caused the largest reduction in performance, regardless of flanker type."

\section{Typos}

Abstract line 13: ad > and

pg. 3 under Statistics: Benferroni > Bonferroni

\section{References}

1. Atkinson J, Anker S, Evans C, Hall R, et al.: Visual acuity testing of young children with the Cambridge Crowding Cards at 3 and 6 m.Acta Ophthalmol (Copenh). 1988; 66 (5): 505-8 PubMed Abstract

2. Bedell HE, Siderov J, Waugh SJ, Zemanová R, et al.: Contour interaction for foveal acuity targets at different luminances.Vision Res. 2013; 89: 90-5 PubMed Abstract | Publisher Full Text

3. Bernard JB, Chung ST: The dependence of crowding on flanker complexity and target-flanker similarity.J Vis. 2011; 11 (8). PubMed Abstract | Publisher Full Text

4. Danilova MV, Bondarko VM: Foveal contour interactions and crowding effects at the resolution limit of the visual system.J Vis. 2007; 7 (2): 25.1-18 PubMed Abstract | Publisher Full Text 5. FLOM MC, WEYMOUTH FW, KAHNEMAN D: VISUAL RESOLUTION AND CONTOUR INTERACTION.J Opt Soc Am. 1963; 53: 1026-32 PubMed Abstract

6. Hanus D, Vul E: Quantifying error distributions in crowding.J Vis. 2013; 13 (4): 17 PubMed Abstract | Publisher Full Text

7. Jeon ST, Hamid J, Maurer D, Lewis TL: Developmental changes during childhood in single-letter acuity and its crowding by surrounding contours.J Exp Child Psychol. 2010; 107 (4): 423-37 PubMed Abstract | Publisher Full Text

8. Liu L, Arditi A: How crowding affects letter confusion.Optom Vis Sci. 2001; 78 (1): 50-5 PubMed Abstract

9. McGraw PV, Winn B: Measurement of letter acuity in preschool children.Ophthalmic Physiol Opt. 
1995; 15 Suppl 1: S11-7 PubMed Abstract

10. Simmers AJ, Gray LS, McGraw PV, Winn B: Contour interaction for high and low contrast optotypes in normal and amblyopic observers.Ophthalmic Physiol Opt. 1999; 19 (3): 253-60 PubMed Abstract

Competing Interests: No competing interests were disclosed.

I confirm that I have read this submission and believe that I have an appropriate level of expertise to confirm that it is of an acceptable scientific standard, however I have significant reservations, as outlined above.

Reviewer Report 06 June 2016

https://doi.org/10.5256/f1000research.9224.r14036

(C) 2016 Norgett $\mathbf{Y}$. This is an open access peer review report distributed under the terms of the Creative Commons Attribution License, which permits unrestricted use, distribution, and reproduction in any medium, provided the original work is properly cited.

\section{Yvonne Norgett}

Anglia Vision Research, Department of Vision and Hearing Sciences, Faculty of Science and Technology, Anglia Ruskin University, Cambridge, UK

The title and abstract are appropriate and accurately reflect the content of the article. Study design and methodology are sound and reflect the aims of the study. The conclusions are valid.

Some minor points for correction:

Introduction p.2- the author should correct the references to the 2 papers authored by Norgett and Siderov. The 2014 paper did not use commercially available tests and the 2011 paper did not have adult participants.

Methods Please confirm if the participants wore their spectacle correction during the trials. Statistics p.3. spelling error 'Bonferroni'.

In the last complete sentence on p.3, the sentence would read better with the word 'from' substituted with 'than', to read '...performance with top and bottom bars was significantly lower than unflanked conditions...'

Table 1: The central column should have units- (letter-widths). Decimal places within the table should be consistent.

Discussion spelling error in the last line of p.7- Sonksen

First sentence of p.8 'currently available test' should be 'tests' plural.

First sentence on 2 nd column should read 'crowding magnitude differs' rather than 'differ'.

Competing Interests: No competing interests were disclosed.

I confirm that I have read this submission and believe that I have an appropriate level of expertise to confirm that it is of an acceptable scientific standard. 
The benefits of publishing with F1000Research:

- Your article is published within days, with no editorial bias

- You can publish traditional articles, null/negative results, case reports, data notes and more

- The peer review process is transparent and collaborative

- Your article is indexed in PubMed after passing peer review

- Dedicated customer support at every stage

For pre-submission enquiries, contact research@f1000.com 